\title{
The Impact of Modernization on the Traditional Social Status of Senior Citizens in Pakhtun Culture
}

\author{
Hamid Alam \\ Department of Social Work \\ University of Malakand \\ Muhammad Saeed \\ Department of Sociology \\ University of Malakand
}

\begin{abstract}
This paper reflects the impacts of modernization on the social status of senior citizens in the Khyber Pakhtunkhwa province of Pakistan. The Pakhtun culture dominated by patriarchal traditional values embedded in the Pakhtunwali is under the influence of modernization. To know the impact of modernization on the social status of senior citizens in Pakhtun culture, data was collected through in-depth interviews/ interview guide in Hayatabad district Peshawar of Khyber Pakhtunkhwa .The respondents were identified through purposive sampling technique. The traditional status of elders is rapidly changing owing to the changing trends in attitudes, familial relations, individualism, women empowerment and migration as attributes of modernity and technological advancement. This change of the traditional structure puts immense pressure on the economic status of senior citizens. Thus due to the weakening of traditional authority, mutual support system and lack of pension schemes, senior citizens are now on one hand confronted with poverty and lower economic positions while on the other hand they are unable to catch up with the changing circumstances. Further, low economic position of the senior citizens is intertwined with other problems such as non-involvement in the decision making processes at home, abuse and torment, ageism, inappropriate medication and care, substandard diet and accommodation.
\end{abstract}

Keywords: Modernization, Senior Citizen, Old House, Elder Abuse, Social Status, Pension.

$$
\begin{aligned}
& \text { تلخيص }
\end{aligned}
$$

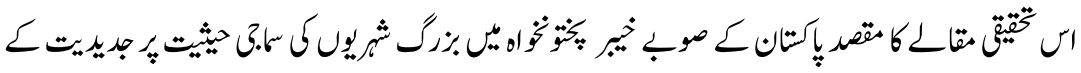

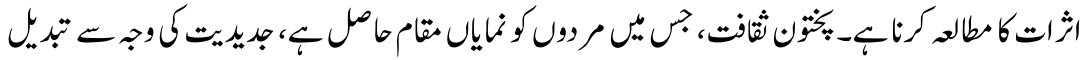

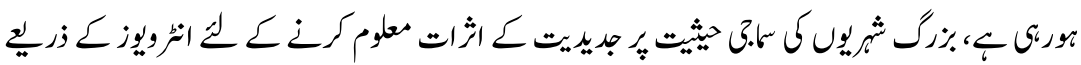

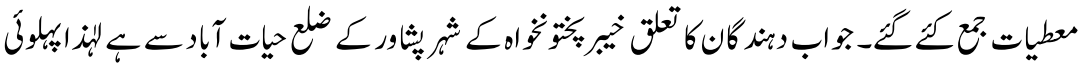

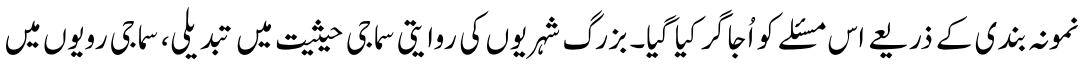

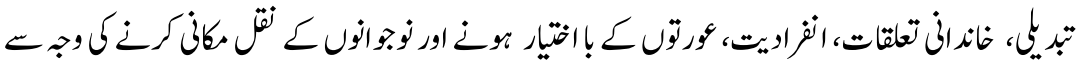




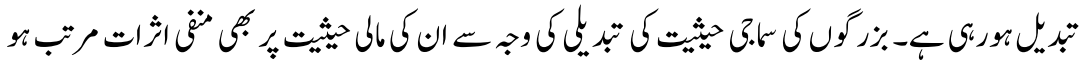

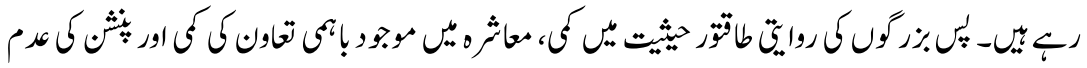

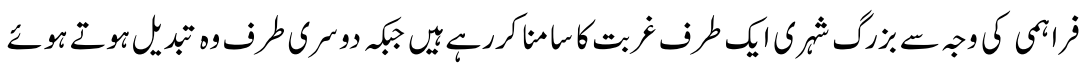

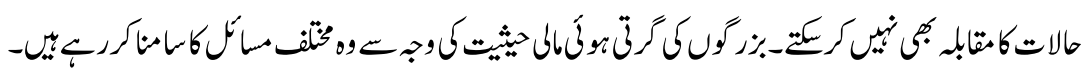

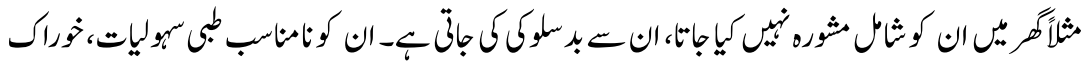

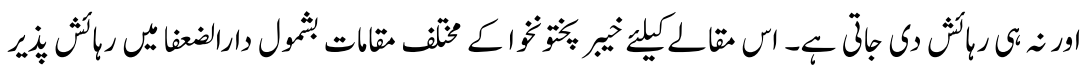

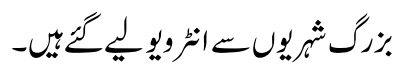

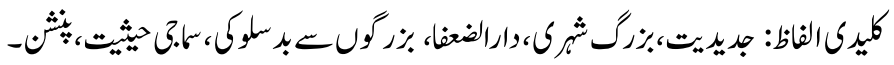

\section{Introduction}

Life expectancy has been increased due to advancement in medicine and health technology which resulted in demographic changes (United Nations, 2003). For example the older population raised from 205 million in 1950 to 606 million in the year 2000 (UNFPA, 1999). Specifically in Pakistan, the sixth populous country of the world, people over 60 years of age are more than 10 million (United Nation Population Fund and Help Age International, 2013). According to the figures of Election Commission of Pakistan (2013) the total number of senior citizens is $12 \%$ of the 86 million registered voters. Further, $40 \%$ of households contain an elderly person (Government of Pakistan, 2002). It is important to mention that on one hand the number of senior citizens is increasing in Pakistan while on the other hand the traditional supporting system regarding elders is vanishing with higher pace of various socio-cultural changes such as mass education, materialistic thinking, decline of religious values, generation gap, poverty, urbanization and industrialization, convergence of joint family system to nuclear family system, competition in the job market, brain drain, migration of youth from rural to urban areas and participation of women in employment (Kajur \& Ekka, 2010; Maqbool, 2012). Resultantly, older people are now considered as outdated, rigid and an economic liability and burden on the family (Verry, 2000). In this changing socio-cultural scenario, elders in Pakistan are unable to catch up with these changes and confronted with various problems. The emerging old age problems are considered the outcome of the introduction of the process of modernization in Pakistani society.

Modernization is the process of change from the rural life style toward the urban way of life. As a society change from traditional and rural way towards modernization, certain socio-cultural changes take place in the society. The key changes introduced in a society due to modernization are introduction of 
industrialization, urbanization and socio-cultural changes such as family nuclearization, materialism, the decline of religious values and the emergence of the concept of ageism and old age problems (Jiloha, 2009).

\section{Theory of Modernization and Old Age Problems}

Modernization as a pattern of social change has influenced each and every aspect of life including old age (Macionis, 2009). The relationship between modernization and its impact on old age was studied by Cowgil in early 1970s.

According to Cowgill modernization brings four types of changes in a society such as improvement of health technology, mass education, urbanization and industrialization. He further claims that besides the multifaceted outcomes of modernity, these changes adversely affect the traditional status and role of the senior citizens.

In addition to the above mentioned changes modernization brings other sociocultural changes such as decline of religious values, break down of joint family system, individualization, women employment and empowerment. These changes adversely affect the high social status of senior citizens (Aboderin, 2004).

As a result of modernization and consequently other social socio-cultural changes, Pakistani society is in a transitory stage regarding old age. Pakistani society is changing from the state of gerontocracy to gerontophobia. In contemporary Pakistani society the senior citizens are facing problems in the form of low social status, poverty/lack of pension and deprivation from the authority of property control, ageism, non involvement in decision making, verbal and psychological abuse (Rehman \& Mohyuddin, 2015).

In contemporary Pakistani society the social status of elderly has changed considerably. The changing social status of elderly is considered the outcome of the squeezing social and economic roles of senior citizens. The senior citizens are losing their hold in running the economic affairs of the house. Moreover in the past children used to learn skills from their parents. In modern times the parental skills are considered outdated by their children and they learn new skills from formal institutions. Thus the children are enable to adopt a profession that is independent of their parents. In addition the professional skills of senior citizens are considered incompatible with the changing economic environment (Salahuddin \& Jalbani, 2006).

In Pakistan, especially in rural areas, senior citizens are deprived by junior family members, particularly sons in the name of affection and care. Removal from the household headship damages their social status as well as financial autonomy. 
Moreover such affection leads to social isolation, depression and demoralization among senior citizens (Ali \& Kiani, 2003).

The old age economic problems are addressed through the practice of old age pension. The objective of pension is to provide financial relief to the senior citizens or financial relief to the family of an individual who loss earning capacity disability or death of wage earning member of the family. In the context of Pakistan the concept of universal pension system is lacking. Old age pension is only for those senior citizens who are retired from public sector employment or working in organized sector. On one side most the senior citizens are deprived of old age pension and on the other hand those who are getting old pension, are living in a hand to mouth situation as pension cannot meet their economic needs (Sabzwari \& Azhar, 2010).

The decision making status of a person determine the independence and autonomous status of person. In the past the senior citizens availed the decision making power particularly in joint family system. All the matters of the house were addressed by the head of the family. Due to modernization the joint family system as well as the decision making authority of senior citizens in on decline. Almost all the issues are decided by the youngsters particularly sons. The young generation sometimes challenge the decision of senior citizens as they are considered ignorant regarding the changing social environment (Ali \& Kiani, 2003).

More over the senior citizens are facing problems in the form of loss of control over property, the emergence of the concept of ageism among the young generation and various types of physical, financial, verbal and psychological abuses (Rehman \& Mohyuddin, 2015).

\section{Methodology}

The aim of this study was to know about the life experiences and sufferings of the older people. In this regard qualitative approach seemed appropriate because it provides the insight and opportunity to the researcher to understand how the social world is experienced, perceived, interpreted and reproduced by the informants (Oakley, 2000). Data was collected from citizens having age 60 years and above. The data was collected through in-depth face-to-face interviewing from 20 respondents (10 males and 10 females) in Hayatabad, town Peshawar of Khyber Pakhtunkhwa province. The respondents were identified and accessed through purposive sampling techniques. Interviews were collected in Pashto language which were latter on verbatimly transcribed into English and the data was thematically analyzed. 


\section{Literature Review}

Soneja (2012) argues that in the South Asian region due to poverty as well as rapidly changing social structure elderly who have weak financial status are considered an economic burden on the family. In Pakistan the retirement funds are limited and government pension schemes are only for those who are employed in government sector (Afzal, 1997). In addition, the government feels uneasy regarding administrative mechanism to pay pension to the retired employees (Wadood, 2013). Out of Ten million senior citizens in Pakistan nearly 0.4 million are getting pension. Mahmood \& Nasir (2008) document that dependence of the elderly population on the government sponsored schemes is increasing due to the squeezing familial bonds. Under such circumstances the need of pension for senior citizens is widely realized in Pakistan; however the approval of the Universal Pension Scheme and Senior Citizen Bill is still pending in the parliament since 2007, for which they often make protests (Ali, 2013).

Khan et al (2003) notes that elders who have some source of personal income or property usually live a prosperous life. In the South Asian cultures parents usually at older age hand over the control of property to their children, particularly to sons (Raju, 2002). However, in the traditional Pakhtun society this practice has least effects on the social status, respect and care of older parents. But in the modern times, loss of property control can exacerbate the lives of older parents and mostly leads to loss of social status.

Chan (2005) argues that men and women experience old age differently because of their different roles and responsibilities. In traditional societies women do domestic chores so they do not face a new challenging situation in their old age. Further older women, particularly mothers usually have strong bonds with their family members and submissive nature than men which help them in their social adjustment. However women face more economic problems than men. Moreover in cultures where men are dominant the social exclusion of older men from the main stream has social as well psychological implications for them. For example in sub-Sahara Africa older men are facing troubling situation because of the change in their income generating activities while woman on the other hand can continue petty trading activities which require less efforts (WHO, 1999). This to some extent is also true in Pakistan.

In the modern world, characterized by competition for job and loss of income as well as loss of control over income generating sources leads to dependency of the older (Kujur \& Ekka, 2010). Presently the social status of elders is largely linked with their economic position, particularly in industrial and modern societies (Kujur \& Ekka, 2010). Economic dependency of older people adversely affects their status and lives. In a research study in Africa it was found that poverty is 3 
times higher among elderly population than the younger population (Ali \& Kiani, 2003). This is very much true in the context of Pakistani society, which is in transitional stage from traditional culture to modernization. Under such situation the financial dependence of elders is increasing on government (Mehmood \& Nasir, 2008). Keeping in view the financial problems of elders the government of Pakistan has recently taken some initiatives to support older population. For example the government of Pakistan invited applications for a monthly stipend of Rs 500/- from those who have crossed the age limit of 70 years (Daily Aaj, 25-102012). The parents are confronted with vulnerable position, particularly when their children themselves are poor and over-burdened to care of them (Sulman, 2008). The informants also strongly supported the interdependence of their social status with their economic position.

Ageism is the process of systematic stereotyping and discrimination against senior citizens (Cuddy and Fiske, 2002). In this regard Robertson (1981) documents that generally in traditional societies older people usually have high status but with the introduction of modernization in society, gradual decrease occur in their social status. Ageism is not only itself a socio-psychological problem but it also initiate other problems as well (Biggs, 1996; Naqvi, 2013). Ageism may be the result of different factors including discrimination and the misconception of parental role by the children. In this regard an Indian District court in Barmeter district of Rajistan province sent three sons of a person to jail on account of ignoring parent's needs. On the petition of the father, the court directed his six sons to take care of their father. Three of them obeyed the order but the remaining three refused the order with the remarks that during their early childhood their father did not fulfill their needs properly so now in his old age we are not ready to take care of him (BBC, 2012). Such misconceptions also prevail in Pakhtun culture in the modern times culturally and socially defined roles of the people including elders are changing (Hess et al., 1996). For example, in traditional societies where industrialization is lacking, the elders are bestowed with responsible leadership role and decision making on account of their experience and wisdom. However technological development, industrialization, urbanization and westernization wrench this status from elders (Gulzar et.al, 2008).

In the context of Pakistani society also the decision making process which was dominated by elders is on decline. On one hand, due to education, women now persistently negotiate the powerful spaces both at domestic and public level and getting empowerment, while on the other hand there is a growing concern among the male junior members regarding the full control and dominance of patriarch. Such alteration has altered the decision making power of senior citizens. Weaker financial position and illiteracy/lower qualification make elders more vulnerable regarding decision making process. 


\section{Results and Discussion}

According to the findings of this research study there is a close association between modernization and the social status of senior citizens. Modernization leads to family nuclearization, materialistic attitudes of young generation, ageism, economic dependency of senior citizens and their non involvement in decision making. The changes brought about by modernization ultimately lead to the decline in the social status of senior citizens.

\section{Modernization and the Status of Senior Citizens}

The impact of modernization on senior citizens were studied by Cowgill and presented the theory of modernization. The process of modernization adversely affects the social status of senior citizens.

Khan Bahadar, a male interviewee of the current study told that due to the introduction of changes in the society, he is not happy with his social status. In the modern time his learned skills are considered outdated and as a result he is dependent on his son for his needs.

"I am not happy because I am dependent upon my sons. When I was young I had my own earning and had a happy life, a status and was living a life like kings. But when I became old I lost my status in the eyes of my wife, children and other around".

Economic independence has close association with the social status. With growing age the senior citizens are unable to get proper employment and thus are economically depended upon family members. However, negative attitudes toward elders unemployment/economic dependency, prevail in the poor and lower-middle class families. In such families older men and women are expected to put their share while participating in less laborious income generating activities.

Kamal, a male respondent who was a daily worker, said:

"I worked as a laborer for the last 30 years and sustained my family. When I became older and was unable to do hard work I began to do security at night in a house of my relative while during the day time I used to look after the grandchildren and the cattle of the house. It is difficult but I have to do so, otherwise they (my family members) mistreat me and call me with bad names". 
In poor families, elders try to continue earning and sustain their families. In case of failure to participate in income generating activities, they are confronted with diverse sufferings.

Researches show a strong association between economic dependency and health status of senior citizens. For example Soneja (2012) found that women with no income are worse sufferers. Usually women do not express their health needs due to economic inconvenience and fear of rejection by the family members. Some of my respondents talked about this. For example Ms. Bakht Rana, mentioned:

"Though my sons take care of my medication. However they abuse me with the remarks that I want to become young”.

Another respondent Mr. Munir told:

"Our family depends upon earning sons. If they are happy they fulfill our needs otherwise not".

\section{Lack of Welfare Services and Pension Schemes for Senior Citizens}

During data collection most of the respondents of this study expressed their views regarding the lack of old age public welfare services. On one side the attitudes of young generation have become materialistic and on the other hand there are limited welfare services for senior citizens which may minimize their sufferings. Old age pension is there only for those senior citizens who have served the government of Pakistan. Thus economic dependence in old age adversely affects the social status of senior citizens. A respondent expressed his views in this way

"If I had pension, I could fulfill my health needs"

On the other hand some of the families utilize the old age pension of their retired members for running the affairs of the house.

For example Mr. Wadood, who was a retired government peon, told:

"I was drawing a monthly pension of Rs. 1800/- month which was nothing to cover all my expenses and medications. When I got sick and was unable to stand in the long queue in the bank I authorized my son to draw the pension and thus I lost it... I should not have done it...He (my son) is not giving a single penny to me".

In Pakistan, on one side such a nominal pension cannot cover the basic needs of retired person. On the other hand it is more shocking when the pension money is lost as mentioned by Mr. Wadood. People, particularly at older age, are hesitant to 
report such cases to police and community because these are considered extremely private. Lack of pension is not the sole economic hurdle; the traditional economic set up which supported the senior citizens is also changing and disfavors the senior citizens. For example the loss of control over property brings negative consequences for senior citizens.

\section{Modernization Leads to Loss of Property Control}

In the modern capitalistic world everything is centered around economy and the concept of "Old is Gold" is vanishing away in Pakistani cultures (Rehman \& Mohyuddin, 2015). In the past older people were considered icon of experience and knowledge and the young generation was supposed to learn from them. However in modern time this thinking has gone and their experience is considered useless (Raju, 2004).

According to the respondents modernization has wrenched property control from the senior citizens. In the past property was in the control of senior citizens, but now it is not possible to retain the control of property at old age. For example a respondent Mr. Wadood told:

"If I had property and Bank Balance then perhaps they (my sons) would not have not abused me".

In Pakistani society, particularly in the urbanized areas, the respect and status of parents is usually linked with their control over the financial resources including property as reflected in the above statement of Wadood. However those families which are less educated as well as less modern, still obey and respect their elders. For example a female interviewee, Ms. Kayenat Bibi who is illiterate and economic weaker as well, commented:

"Although I am a widow and economically poor but my children respect me because I have socialized them according to the Islamic teachings".

The Pakhtun culture as well as religion Islam both stress upon the respect of parents and elders. Regarding the respect, polite treatment and other rights of the parents there are at least 15 verses in the holy Quran. Similarly there are numerous sayings of the Prophet Muhammad (PBUH) regarding the parent's rights. However due to modernization the religion is losing its control and the religious teachings regarding the respect and care of elders are minimizing. Those who follow the Pakhtun culture or religion Islam in the real sense, give due status to their older family members and considers it an obligation. The Pakhtun culture is also famous for gerontocracy. However due to modernization Pakhtun culture is in transitory stage regarding the care and respect of senior citizens. 


\section{Modernization Directs Ageism}

The collected data shows that due to modernization certain changes take place in society. Such changes include education of young generation, inappropriate attitudes of young generation toward the seniors and the financial autonomy of young generation due to professional skill. These changes direct ageism against senior citizens. The literature also shows that the improved qualification of young generation leads to ageism against senior citizens. According to Cowgill theory of modernization (1986) after modernization mass education of young generation adversely affects the status of elders in a society. Children do not involve their parents in decision making and consider them as orthodox and idle when the parents are illiterate or less qualified than their children. Regarding the relationship between academic qualification and decision making a respondent expressed his views as

"My children are disobedient and do not respect me. They say I am illiterate, idle and do not understand the changing trend of the modern time".

Another male respondent Mr. Wadood, who was expelled from house by his sons, told:

"My sons labeled me as a lunatic and did not want to accommodate me because they blamed me of talkativeness after I became paraplegic”.

A female interviewee Ms.Gul Mena was also not happy with the attitudes of her sons, told:

"My children blame me of irritability and childish behavior. I think my behavior is not irritable and childish. In fact my children are unable to fulfill their responsibilities toward me and through such blames they want to escape themselves from their responsibilities".

\section{Modernization and Decision Making}

In the past the senior citizens availed the decision making power. All the matters of the house were decided by the head of the family. Due to modernization the decision making authority of senior citizens in on decline in Pakistani society. Almost all the issues are decided by the youngsters particularly sons. The young generation sometimes challenge the decision of senior citizens as they are considered ignorant regarding the changing social environment (Ali \& Kiani, 2003). 
Mr. Ikram who was illiterate and unemployed respondent told:

"My sons do not involve me in decision making, they say that they can decide better because they are qualified and understand the modern trends".

However compared to women, men are comparatively more active in decision making process, particularly in rural areas (Khan et al., 2003).

A female interviewee, Ms. Mamoona, living in rural area, mentioned:

"My husband does not involve me in the family matters. He says it is a taboo to ask women in taking familial decisions".

In traditional and religious families the economic status and education of older people has nothing to do with their decision making power. In such sittings older people are highly adored. For instance one of the female interviewee, Ms. Kayenat Bibi, who was a widow, poor and illiterate, having religious environment at her home said:

"In the absence of my husband I play his role. I decide all the matters in the house".

\section{Elder Abuse is the Outcome of Modernization}

Although the older people in Pakistani society are usually respected and obeyed but in recent time due to modernization and the promotion of individualistic and selfish attitudes on the part of young generation, elders are vulnerable to multiple types of abuses such as verbal, physical, economic and psychological (Lai, 2008). Different types of abuses are exercised against elders. For example Dildar et al., (2012) in a research study in Punjab province, found that majority of the respondents $(90 \%)$ of the older had financial abuse which include theft of money and snatch of property, further women face more threatening situation when they refuse to give money to their deviant children. The study further documents that $85 \%$ of the respondents reported psychological abuse such as humiliation and use of harsh behaviour and calling with bad names, while $60 \%$ respondents mentioned that they have experienced physical abuse.

Both older men and women are the victim of abuses, however compared to men, older women are more vulnerable to abuse. For example Garrod (1993) found that men and women were victims in a ratio of 1:3 in United Kingdom. Soneja (2012) conducted a research study in India and found that the second important problem of women is their abuse by daughters-in-law. One reason of the conflict between mother and daughter in- law is to gain the control of the house (Saeed, 2012). 
This is also very much true in the context of Pakhtun culture. For example Bakht Rana, an old female respondent told:

"I have four daughters-in-law but only one of them takes care of me, because she is my blood relative. The remaining three do not like my company and abuse me verbally".

In Pakistani culture the conflict between mother and daughter in-law leads to family nuclearization, which again create problems for the old parents. However if there is blood relationship between both the parties then the abuse of mothersin-law is either lacking or its intensity is low.

A female respondent Ms. Gul Mena commented as:

"I have never experience physical abuse in the house however I frequency face verbal abuse particularly abusive language of my daughters-in-law regarding my weaker family background and weaker physique".

In Pakhtun society verbal abuse of elders is getting acceptance, however physical abuse of older parents and elderly is considered a taboo and resultantly there are limited incidents of physical abuse.

\section{Conclusions}

Modernization is an inevitable social process and is considered a prerequisite for development. However it replaces the existing social set up with the new one. The elders are unable to adjust themselves with the emerging social environment. More over due to modernization the senior citizens are unable to maintain a reasonable economic status. Due to modernization the elders are not in a position to play an active role in different spheres of life. This process leads to the creation of problems for the senior citizens in the form of ageism, non involvement in decision making, elder abuse generation gap between the young and old.

\section{Recommendations}

In order to restore the social status of senior citizens in Pakhtun society the following measures are suggested.

- To introduce old age pension for all senior citizens.

- Modernization need to be introduced according to the norms of the society.

- The religious leaders should inculcate the Islamic concept of parents rights to the young generation. 
- The state should legislate for the wellbeing of senior citizens.

- Parents should keep a part of their property as an economic security for their old age.

\section{References}

Aboderin, I. (2004). Modernisation and Ageing Theory Revisited: Current Explanations of Recent Developing World and Historical Western Shifts in Material Family Support for Older People. Ageing \& Society. pp 29-50 DOI: $10.1017 / \mathrm{S} 0144686 \mathrm{X} 03001521$

Afzal, M. (1997). Population Ageing Issues in Pakistan: A Further Analysis, Some Problems and Issues of Older Persons in Asia and Pacific. United Nations. ESCAP Asian Population Studies, New York. pp.44-80

Akhtar, Syed H. (n.d.). The Status of Parents in Islam http://www.islamquery.com/ documents/status-of-parents-in-islam.pdf

Ali, S.M. \& Kiani, M.F.(2003). Ageing and Poverty in Pakistan. Pakistan Institute of Development Economics, Islamabad.

Ali, Z. (2013). Senior Citizens Bill 2007. Daily Dawn, 11-12-2012.

BBC (2012). Three sons sent to jail for not caring their father [translated from Urdu]. Available at: www.bbc.co.uk/urdu/india/2012/11/121101_three sons_jailed_mb.shtml) retrieved on 06-06-2013

Biggs. S. (1996). A Family Concern: Elder Abuse in Britian Social Policy. Critical Social Policy. 16. pp. 63-88.

Chan, A. (2005). Formal and Informal Intergenerational Support Transfers in South-Eastern Asia. In Proceedings of the United Nations Expert Group Meeting on Social and Economic Implications of Changing Population Age Structures, New York. pp 51-53

Cowgill, D. O. (1986). Aging and Modernization: A Revision of the Theory. In F. Jaber Gubrium (E.ds), Communities and Environmental Policy. Springfield, III: Charles Thomas. pp.124-146.

Cuddy, A.J. C. and Fiske, S.T. (2002). Ageism: Stereotyping and Prejudice Against Older Persons. London: The MIT Press. pp. 3-26.

Daily Aaj. (25-10-2012). Ministry of Social Welfare and Women Development Khyber Pakhtunkhwa Pakistan. p.06 
Dildar.S., Saeed, Y. \& Sharjeela. (2012).Exploratory Study of the Nature of Violence Against Elderly indistrict Gujrat, Pakistan. Journal of Academic Research International, vol.02:3, pp.661-69.

Election Commission of Pakistan. (2013). Report on the General Elections 2013 available at: https://www.ecp.gov.pk/Documents/General\%20Elections \%202013\%20report/Election\%20Report\%202013\%20Volume-I.pdf

Garrod,G. (1993). The Mistreatment of Older People. Journal of Generations Review, vol.3:4. pp.9-12.

Government of Pakistan. (2002). Ageing in Pakistan: A Situation Analysis. Ministry of Women Development, Social Welfare and Special Education, Government of Pakistan.

Gulzar, F.,Zafar, M. I., Ahmad, A. \& Ali, T. (2008). Socio-Economic Problems of Senior Citizens and their Adjustment in Punjab, Pakistan. Journal of Agricultural Sciences, vol.45:1, pp.138-144.

Hafeez, S. (1991). The Changing Pakistani Society. Lahore: Royal Book Company.

Hess, B.B., Markson, W. E. \& Stein, J.P. (1996). Sociology, Aging and the Life Course. London: Allyn and Bacon.

Imam, A. (2013). No Country for Old Men, Daily Aaj, 29-03-2013. p.08

Jiloha, R. C. (2009). Impact of Modernization on Family and Mental Health in South Asia. DELHI PSYCHIATRY JOURNAL Vol. 12 No.1, pp. 42-60

Kajurr, D. and Ekka, P.R.(2010). Socio-Economic Status of elderly people in India. International Referred Research Journal, vol.5:12, pp.3-6

Khan, J. A., Khan, A.Q., Qureshi, H., Rizwanullah. \& Harris, K. (2003). Survey on the Health and Living Conditions of the Elderly Population of Pakistan. Pakistan Medical Research Council Islamabad. pp. 01-34

Lai, S. (2008). Community Mobilization Empowering Seniors Against Victimization Elder Abuse and Policing Issues: A Review of the Literature, Submitted to: National Crime Prevention Centre of Canada Public Safety Canada.

Macionis, J. J. (2009), Sociology, Dorling Kindersley (India) Pvt. Ltd. P 629. 
Mahmood, N. \& Nasir, M.Z. (2008). Pension and Social Security Schemes in Pakistan, Some Policy Options. Pakistan Institute of Development Economics, Islamabad.

Maqbool, S. (2012). Pakistan's Ageing Population to Rise from Current, The News, October $2^{\text {nd }}$, p. 13 .

Naqvi, L. J. (2013). Put a Roof Over their Heads. Daily News, retrieved on 29 the February, 2016.

Oakley, A. (2000) Experiments in Knowing: Gender and Methods in Social Sciences. New York: The New Press.

Raju, S.S. (2002). Health Status of the Urban Elderly: A Medico-social Study, Delhi: B. R. Publishing Co.

Raju, S. S. (2004). Studies on Ageing in India: A review, Institute for Social and Economic Change. Bangalore United Nations Population Fund, New DelhiInstitute of Economic Growth, Delhi

Rehman, I. \& Mohyuddin, A. (2015). Social Issues of Senior Citizens. The Explorer Islamabad: Journal of Social Sciences, 8(1), 301-306.

Robertson, J. (1981). Sociology, Inequality of Gender and Age, (2 ${ }^{\text {nd }}$ Edition), Worth Publishers, Inc. New York, p.332.

Sabzwari, S. R. and Azhar, G. (2010). Ageing in Pakistan-A New Challenge Ageing. Available at: http:/ /memberfiles.freewebs.com/84/90/65819084/ documents/ Aging\% 20in\%20Pakistan. pdf, retrieved on March, 20, 2018.

Saeed, M. (2012). Pakhtun Men's Perceptions of the Conditions Promoting Domestic Violence in Their Culture.Unpublished $\mathrm{Ph}$. D dissertation, University of York, UK.

Salahuddin, K \& Jalbani, A.A. (2006). Senior Citizens: A Case Study of Pakistan. Journal of Independent Studies and Research (JISR), vol.4:2.

Soneja, S. (2012). Elder Abuse in India. Available at: http://www.who.int/ageing/ projects/elder_abuse/alc_ea_ind.pdf, retrieved on November 13, 2013.

Sulman, N. (2008). The Situation of Elderly Population in Pakistan: Problems and Prospects. Pakistan Journal of Special Education, vol.11:2, pp.01-23 
United Nations.(2003). World Population Prospects: The 2002 Revision. Available at: http://www.un.org/esa/population/publications/wpp2002/ WPP2002-HIGHLIGHTSrev1.PDF, retrieved on November 14, 2013.

UNFPA (1999). Population Ageing: Challenges for Policies and Programs in Developed and Developing Countries. The United Nations Population fund, Population and Family Study Center New York and Brussels.

Verry, D. (2000). Lifelong Learning as an Affordable Investment. Available at: http://www.oecd.org/education/innovation-education/1917560.pdf, retrieved on September 5, 2013

Wadood, A. (2013).Smart Card, Pensioners Kay Jeebon Par Daka (Smart Card: A Robbery Over the Pockets of Pensioners) Daily Aaj, $23^{\text {rd }}$ July

WHO. (1999). Men Ageing and Health Achieving Health across the Life Span, Geneva, World Health Organization.

Hamid Alam is an Assistant Professor in the Department of Social Work, University of Malakand, Khyber Pakhtunkhwa, Pakistan.

Muhammad Saeed is an Assistant Professor in the Department of Sociology, University of Malakand, Khyber Pakhtunkhwa, Pakistan. 